\title{
Method of optimal parameters control in three- phase separator using fuzzy controller
}

\author{
E.A. Muravyova \\ Ufa State Petroleum Technological University \\ Branch in Sterlitamak, Russian Federation \\ Sterlitamak, Russia \\ muraveva_ea@mail.ru
}

\author{
M.I. Sharipov \\ Ufa State Petroleum Technological University \\ Branch in Sterlitamak, Russian Federation \\ Sterlitamak, Russia \\ sharipovm@mail.ru
}

\begin{abstract}
The article is devoted to the synthesis of a fuzzy regulator for optimal regulation of parameters in a three-phase separator of Heater-Treater type in whichthe liquid-gas mixture is separated, heated, and oil emulsion is split into formation water and oil. These processes are complicated by the fact that an oil-water phase is converted into a stable emulsion (a disperse system of finely distributed water droplets in oil) for desalting and dewatering of which separation of disperse oil medium from disperse water phase is required. The solution to this problem is impossible without introduction of an automated system. And not only use of the automated system, but an optimal process management is required,. During optimization, a chosen method and an obtained optimal structure of the process control system is of great importance. In conditions where development of a control system for a complex object is complicated by the fact that it is impossible for the latter to develop accurate mathematical models using integral-differential equations, fuzzy logic is becoming a tool allowing development of the control system for the said complex object. A mathematical model allowing simulating processes taking place inside a system is obtained. The study of the simulation model makes it possible to obtain information that can be used to control a real object. To ensure the best quality of the automated process control system, methods for optimization of its structure are presented. Examples demonstrating efficiency of the proposed methods are given.
\end{abstract}

Keywords-fuzzy logic, fuzzy controller, optimization, mathematical model, reference points, level, terms.

\section{INTRODUCTION}

Fuzzy sets are a tool enabling to develop models for controlling complex objects which do not always make it possible to develop precise mathematical models using integro-differential equations.

In this article, we will describe mathematical model of a three-phase separator "Hiter-Triter" type, we will consider methods for optimization of the control system structure using the fuzzy controller.

\section{BRIEF CHARACTERISTICS OF THE THREE-PHASE SEPARATOR OF "HITER-TRITER" TYPE}

The three-phase separator "Hiter-Triter" type is used for receiving commercial oil from oil wells, for separation of well product for preliminary dehydration. It is capable to replace the installation consisting of several parts. The installation can be operated in severe climatic conditions at a temperature down to $-60{ }^{\circ} \mathrm{C}$.

The separator of "Hiter-Triter" type is the horizontal cylindrical installation with the elliptic bottoms mounted on two saddle supports. On a cylindrical part of the body and the bottoms of the installation, there are process connections, the connections provided for mounting instrumentation and control equipment and hatches. On the bottom (product inlet side), a flange connection of the heater pipes to the body is provided.

For controlling of the oil level and the of phase separation, the installation is equipped with mechanical control valves on the oil and water outlet pipelines. The oil control valve and the valves of the water outlet operate mechanically, using level controllable floats inside the vessel which has the valve attached to it.

In practice, there are cases that some water starts arriving in the oil outlet pipeline due to the fact that the mechanical control valves are unable to perform well their mission so that the operator has no time to adjust the valves in the manual mode because of what the phase separation level is not under control any more, following which the process of separation (dehydration) is to be implemented again. For the problem to be solved, we will set the task to synthesize the controller for the level control. 


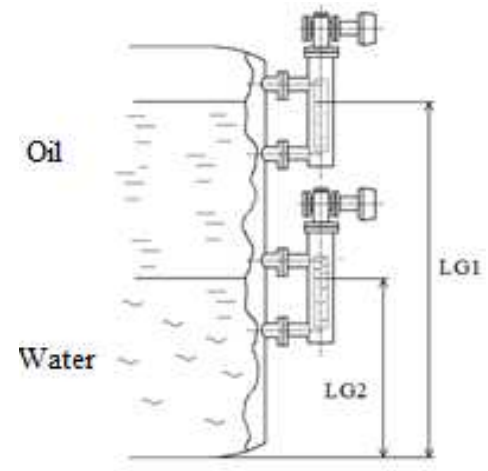

Fig. 1. Level measurement of in the three-phase separator of «Hiter-Triter» type

\section{THE LEVEL CONTROL SYSTEM MODELING IN A THREE-PHASE SEPARATOR OF «HITER-TRITER» TYPE}

\section{A. Production control quality criteria}

Quality of an automated control system is defined by a set of properties providing effective functioning of both the control object, and the controlling device, i.e. of all the control system on the whole.

The properties which make up this set and which have quantitative values are called the control system quality criteria.

The automated system quality may be estimated by criteria such as system synthesis working hours and the computing power (processor time and memory) required for it.

Working hours of the system synthesis in our case involves the time consumption for fuzzy controller development.

In order to reduce working hours, it is suggested using the following methods of optimizing the control system structure using the fuzzy controller:

1) Transition from one fuzzy controller to consecutively connected fuzzy controllers;

2) Transition from one fuzzy controller to fuzzy controllers connected in parallel;

\section{3) Method offeedback exception.}

Application of the said methods results in reduction in number of the rules created in the synthesis of the fuzzy controller, which serves to reduce time consumption for development of the fuzzy controller. Besides at the expense of reduction in the number of rules lowers the computing power requirement is cut down, i.e. less CPU time and memory for data processing are required.

Quality of production of this process is defined by its oil water content, which is to be less than 10 percent. This parameter is constantly controlled at the pump station outlet (PS). This parameter should not exceed the set standard. Oil quality is controlled at the top level of automatic control system.

\section{B. Description of the three-phase separator model of "Hiter- Triter" type}

As was mentioned, the quality of this process product is defined by its water content. To control the said parameter within this article, we will use the «Hiter-Triter» separator type as the above mentioned installation separates oil from water.

We will create this separator model, where the correlation between the liquid and water levels and the emulsion flow rate, the composition of the emulsion and the valves opening gap for oil and water outlet shall be considered. The mathematical model allows simulating the processes occurring within the system. Studying the simulation model makes it possible to obtain both the data and information as to be used to control a real object.

Designations of the model parameters: $\mathrm{F}_{\mathrm{e}}$ - consumption of water-gas-oil emulsion, $\mathrm{m}^{3} / \mathrm{h} ; \gamma_{\mathrm{o}}$ - volume fraction of oil in emulsion, percentage; $\gamma_{\mathrm{w}}-$ volume fraction of water in emulsion, percentage; $\gamma_{\mathrm{g}}$ - volume fraction of gas in emulsion, percentage; $\alpha_{0}$ - valve opening gap at the oil outlet, percentage; $\alpha_{\mathrm{w}}$ - valve opening gap at the water outlet, percentage; LG1 - liquid level, m; LG2 - water level, m.

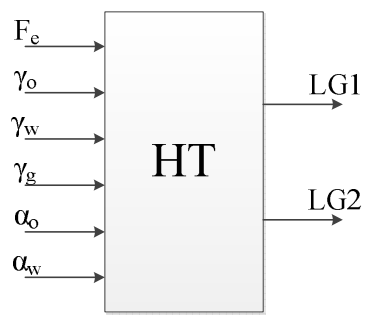

Fig. 2. Conceptual model of the "Hiter-Triter" separator

Separator productivity liquid-based is $6848 \mathrm{~m}^{3} / \mathrm{d}$, and maximum permissible separator productivity $11810 \mathrm{~m}^{3} / \mathrm{d}$. Let us make it as a point that the emulsion gas content there is 5 percent, after the I separation step. The volume fraction of water as related to liquid can be from 60 to 98 percent. Therefore, a volume fraction of oil is from 2 to 40 percent. The inflow of emulsion will be equal to $7208,4 \mathrm{~m}^{3} / \mathrm{d}(300,35$ $\mathrm{m}^{3} /$ hour), and the maximum permissible inflow is 12431,6 $\mathrm{m}^{3} / \mathrm{d}\left(517,98 \mathrm{~m}^{3} /\right.$ hour$)$.

Liquid level in the installation is to be maintained within the range of $0,4-0,8 \mathrm{~m}$, and water level within the range of $0,6-$ $0,8 \mathrm{~m}$.

The level control model will look like:

$$
\left\{\begin{array}{l}
\frac{d L G 2}{d t}=k_{1} \times\left(F_{w 1}-F_{w 2}\right) \\
\frac{d L G 1}{d t}=k_{2} \times\left(F_{o 1}-F_{o 2}+F_{w 1}-F_{w 2}\right) .
\end{array}\right.
$$

Here $\frac{d L G 2}{d t}-$ water level variation, percent $/ \mathrm{h}$; 
$\frac{d L G 1}{d t}-$ liquid level variation, percent $/ \mathrm{h}$;

$k_{1}, k_{2}-$ scale factor, percent $/ \mathrm{m} 3$;

$F_{w 1}-$ inlet water flow rate, $\mathrm{m} 3 / \mathrm{h}$;

$F_{w 2}$ - outlet water flow rate, $\mathrm{m} 3 / \mathrm{h}$;

$F_{o 1}-$ inlet oil flow rate, $\mathrm{m} 3 / \mathrm{h}$;

$F_{o 2}$ - outlet oil flow rate, $\mathrm{m} 3 / \mathrm{h}$.

Scale factor calculation.

The volume of the three-phase separator of «Hiter-Triter» type is $80 \mathrm{~m}^{3}$. The volume occupied by the liquid level is within $0,4-0,8 \mathrm{~m}$ shall be considered as equal to $10 \mathrm{~m}^{3}$.

Therefore:

$$
k_{1}=\frac{100}{10}=10 \% / \mathrm{m}^{3}
$$

The volume occupied by the phase separation level being within $0,6-0,8 \mathrm{~m}$ shall be considered as equal to $20 \mathrm{~m}^{3}$.

Therefore:

$$
k_{2}=\frac{100}{20}=5 \% / \mathrm{m}^{3}
$$

The inlet water flow rate shall be calculated by the formula:

$$
F_{w 1}=F_{e} \times \gamma_{w}
$$

where $\mathrm{F}_{\mathrm{e}}$ - water-gas-oil emulsion flow rate, $\mathrm{m}^{3} / \mathrm{h}$; percentage.

$\gamma_{\mathrm{w}}-$ water volume fraction in the emulsion,

The inlet oil flow rate shall be calculated by the formula:

$$
F_{o 1}=F_{e} \times \gamma_{o}
$$

where $\mathrm{F}_{\mathrm{e}}$ - water-gas-oil emulsion flow rate, $\mathrm{m}^{3} / \mathrm{h}$;

$\gamma_{o}-$ oil volume fraction in the water-gas-oil emulsion, percentage.

The outlet water and oil flow rate depends on valves opening gap. Therefore, functions are obtained as follows:

$$
\begin{aligned}
& F_{w 2}=f\left(\alpha_{w}\right), \\
& F_{o 2}=f\left(\alpha_{o}\right),
\end{aligned}
$$

where $\alpha_{0}$ - oil outlet valve opening gap, percentage;

$\alpha_{\mathrm{w}}$ - water outlet valve opening gap, percentage.

In figure 3 the fuzzy controller conceptual model for controlling of control valves is presented.

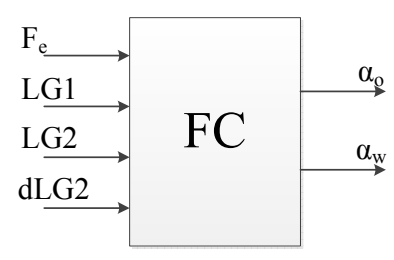

Fig. 3. The fuzzy controller conceptual model

The conceptual model parameters designations look like:

$\mathrm{F}_{\mathrm{e}}$ - water-gas-oil emulsion flow rate, $\mathrm{m}^{3} / \mathrm{h}$;

LG1 - liquid level, m;

LG2 - water level, $\mathrm{m}$.

dLG2 - water level variation, percent/tact;

$\alpha_{o}-$ oil outlet valve opening gap, percentage.

$\alpha_{\mathrm{w}}$ - water outlet valve opening gap, percentage.

Let us describe input linguistic variables «Water-gas-oil emulsion flow rate», «Liquid level», «Water level», «Water level variation» and outputs «Oil outlet valve opening gap», «Water outlet valve opening gap».

This fuzzy controller synthesis is hampered by the fact that it necessities quite a number of rules to be built, viz. $5^{4}=625$ rules.

\section{OPTIMIZATION OF THE CONTROL SYSTEM STRUCTURE USING THE FUZZY CONTROLLER}

The control theory has always emphasized the problem of mathematical models and control algorithms synthesis lacking sufficient information on the control object and on its valid signals and interferences influencing this object.

In the course of time, it has become clear that for such systems controlling automatic control theory classical methods are not any adequate so that novel methods and approaches must be developed. One of such approaches is based on fuzzy sets and fuzzy logic. This approach was first applied showing its efficiency for expert systems creation. Later on it started application to create expert control systems, whereas quite recently its application opened for controller and process control systems synthesis.

The present article will deal with methods of optimization of the control system structure using the fuzzy controller.

\section{A. Method of consecutively connected fuzzy controllers}

This method is perfectly fit when it is best to divide the system into blocks (links). The scheme of this method is shown in figure 4. 


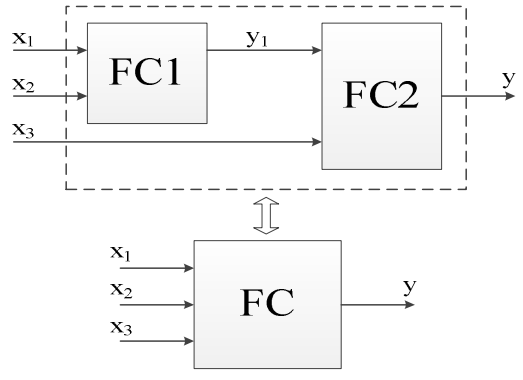

Fig. 4. Structure of fuzzy controllers consecutive connection

Application of this method allows one to reduce working hours of the fuzzy controller synthesis process in case if it is easier to calculate small blocks and to make experiments with them, rather than to make calculations of the big block and to make experiments with it.

The fuzzy controller represents a static link, therefore, consecutive connection of the fuzzy controllers will also be a static link. This statement allows to reduce working hours of the computing process because internal links of the fuzzy controller are necessary only at the stage of its synthesis so that they are not to be calculated during its operation.

One more advantage of this method is the possibility of replacement of one of blocks, in case of system variation, i.e. there is no need to make calculations for all the controller, it is enough to calculate only the new block.

Let us review an example of the number of rules calculation. For the structure presented in figure 4 , it is so to be presumed, that for the input $x_{1} n_{1}=5$ terms, for $x_{2} n_{2}=6$ terms, for $\mathrm{x}_{3} \mathrm{n}_{3}=7$ terms, and for $\mathrm{y}_{1} \mathrm{n}_{4}=8$ terms are described.

Then the number of rules for FC (figure 10) will be equal to:

$$
n_{1} \times n_{2} \times n_{3}=N \text {, }
$$

where $N$ - the number of rules;

$$
n_{1} \times n_{2} \times n_{3}=5 \times 6 \times 7=210 \text {. }
$$

In transition to consecutive connection of the fuzzy controllers (FC1 and FC2) the number of rules will be equal to:

$$
n_{1} \times n_{2}+n_{3} \times n_{4}=N^{\prime},
$$

where $N^{\prime}$ - the number of rules.

$n_{1} \times n_{2}+n_{3} \times n_{4}=5 \times 6+7 \times 8=86$.

This method should be applied in that case when the condition is satisfied:

$$
N^{\prime}<N
$$

\section{B. Method of the fuzzy controllers parallel connection}

This method is applicable in cases where the output parameter of fuzzy controller does not depend on all input parameters. The scheme of this method is presented in figure 5.

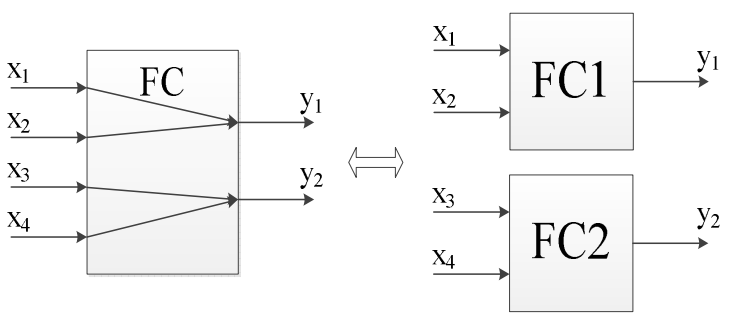

Fig. 5. Structure of the fuzzy controllers connected in parallel

Transition from one fuzzy controller to two parallel fuzzy controllers can promote reduction of the number of rules during synthesis which, in turn, can reduce working hours of the fuzzy controller development.

It also reduces the requirement for the microprocessor that implements the fuzzy controller, and if one is to be more exact it requires less CPU time and memory for data processing.

\section{Method of feedback exception}

The essence of this method consists in transition from the fuzzy controller with feedback to the fuzzy controller without feedback which allows to reduce the number of input parameters owing to which there is a reduction of number of the rules being synthesized at both synthesis and operation of the fuzzy controller.
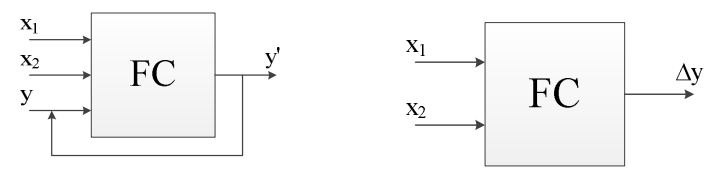

Fig. 6. The fuzzy controller with feedback and without feedback

In practice for compensation of interferences, it is necessary to control the current control action that is to say, for interferences to be reduce it can be necessary either to increase, or to reduce the control action. If the control action depends on its current value, then it is necessary to apply feedback to control the current value.

In case if the control action variation does not depend on the current value, the number of inputs may be reduced the which will lead to reduction of the number of rules.

\section{OPTIMIZATION OF THE FUZZY CONTROLLER FOR CONTROL OF THE SEPARATOR}

For realization of optimal control we will divide the FC conceptual model presented in figure 3 in two parallel ones (figure 7).

Optimization is developedby means of two methods: 
Division of one fuzzy controller in two parallel ones. Therefore the number of rules is reduced to $5^{2}+5^{2}=50$ rules, the reduction of working hours of the fuzzy controller development takes place. As well as computing power requirement is cut down, i.e. less CPU time and memory for data processing are required.

The variation of valve opening gap $\left(\Delta \alpha_{w}\right)$ obtaining at the FC2 output instead of the new value of the valve opening gap of theoutlet water flow rate $(\Delta \alpha)$. This method allows one to reduce the number of input parameters of the FC2, as well as it allows one to reduce the number of rules consequently.

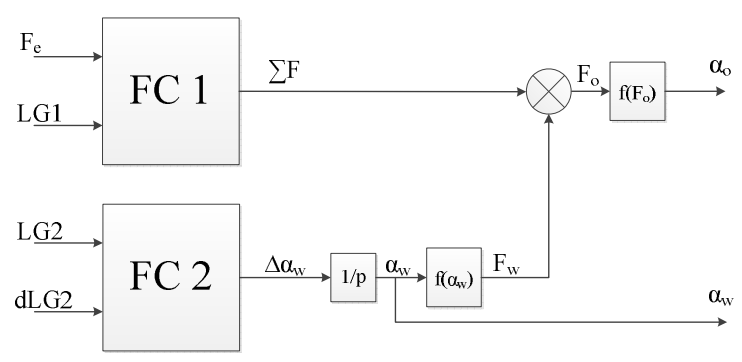

Fig. 7. The block diagram of a control system with parallel fuzzy controllers

The block diagram parameters designations look like: $\mathrm{F}_{\mathrm{e}}-$ water-gas-oil emulsion flow rate, $\mathrm{m}^{3} / \mathrm{h} ; \mathrm{LG} 1$ - liquid level, $\mathrm{m}$; LG2 - water level, m; dLG2 - water level variation, percent/tact; $\sum \mathrm{F}$ - aggregate oil and water outlet flow rate, $\mathrm{m}^{3} / \mathrm{h} ; \Delta \alpha_{\mathrm{w}}-$ variation of the outlet water valve opening gap, percentage; $1 / \mathrm{p}-$ the integrating block for calculating of new $\alpha_{\mathrm{w}}$ value:

$$
\alpha_{w}=\alpha_{w}^{\prime}+\Delta \alpha_{w}
$$

where $\alpha_{w}^{\prime}$ - outlet water valve opening gap before water level variation;

$\alpha_{o}$ - outlet oil valve opening gap, percentage;

$\alpha_{\mathrm{w}}-$ outlet water valve opening gap, percentage;

$f\left(\alpha_{w}\right)$-block using for calculation outlet water flow rate depending on valve opening gap:

$$
F_{w}=f\left(\alpha_{w}\right)
$$

where $\mathrm{F}_{\mathrm{w}}$ - water flow rate, $\mathrm{m}^{3} / \mathrm{h}$;

$\alpha_{\mathrm{w}}$ - water outlet valve opening gap, percentage;

$\mathrm{F}_{\mathrm{o}}$ - oil flow rate, $\mathrm{m}^{3} / \mathrm{h}$;

The inlet oil flow rate shall be calculated by the formula:

$$
F_{o}=\sum F-F_{w},
$$

where $\mathrm{F}_{\mathrm{o}}$ - oil flow rate, $\mathrm{m}^{3} / \mathrm{h}$;

$\sum \mathrm{F}$ - aggregate outlet oil and water flow rate, $\mathrm{m}^{3} / \mathrm{h}$;

$\mathrm{F}_{\mathrm{w}}$ - water flow rate, $\mathrm{m}^{3} / \mathrm{h}$;

$f\left(F_{H}\right)$-block using for calculationoutlet oil valve opening

\begin{tabular}{|c|c|c|c|c|c|}
\hline LG1 & $\begin{array}{r}L \\
\text { G11 }\end{array}$ & $\begin{array}{r}\mathrm{L} \\
\text { G12 }\end{array}$ & $\begin{array}{r}L \\
\text { G13 }\end{array}$ & $\begin{array}{r}\mathrm{L} \\
\text { G14 }\end{array}$ & $\begin{array}{r}\mathbf{L} \\
\text { G15 }\end{array}$ \\
\hline $\mathrm{Fe} 1$ & $\sum F$ & $\begin{array}{l}F_{1}{ }^{\sum} \\
F^{=-4 !}\end{array}$ & $\begin{array}{l}F_{1} \sum^{\sum+2} \\
F_{z}\end{array}$ & $\begin{array}{l}E_{1}=2 \\
E_{z}\end{array}$ & $F_{2} \begin{array}{l}\sum \\
F_{n}^{02 x}\end{array}$ \\
\hline $\mathrm{Fe} 2$ & $F_{z}$ & 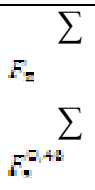 & $\begin{array}{l}F_{1}=\sum^{\sum} \\
F_{9}\end{array}$ & $E^{E_{2}}{ }^{\sum}$ & $F_{2} \begin{array}{l}\sum \\
F_{2}^{2 x}\end{array}$ \\
\hline $\mathrm{Fe} 3$ & $F_{2}$ & $F_{2} \begin{array}{l}\sum \\
F_{2}^{2+2}\end{array}$ & $\begin{array}{l}F_{x}=\sum^{\sum} \\
F_{z}\end{array}$ & $F_{F_{2}: \sum^{\sum}}^{\sum}$ & F. $\begin{array}{l}\sum \\
F_{*}\end{array}$ \\
\hline $\mathrm{Fe} 4$ & $F_{2} \sum$ & 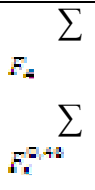 & $\begin{array}{l}F_{m}=4 \\
F_{m}\end{array}$ & 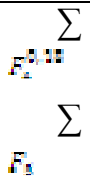 & $F_{*}{ }^{\sum} \sum^{\sum_{2 x}^{2 x}}$ \\
\hline $\mathrm{Fe} 5$ & $F^{\sum}$ & $E_{m} \begin{array}{l}\sum \\
F_{n}=34\end{array}$ & $F_{m} \begin{array}{l}\sum \\
F_{m}\end{array}$ & 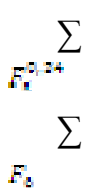 & $F^{\sum}$ \\
\hline
\end{tabular}
gap, depending on outlet oil flow rate.

TABLE I. PRODUCTION RULE BASE FOR FC1

$$
\alpha_{o}=f\left(F_{o}\right)
$$

where $\alpha_{\mathrm{o}}$ - oil outlet valve opening gap, percentage;

$\mathrm{F}_{\mathrm{o}}$ - oil flow rate, $\mathrm{m}^{3} / \mathrm{h}$;

On the basis of optimal model fuzzy controllers were developed.

At the aggregation stage, we calculate the consequent truth degree for some of the rules of fuzzy inference system. At the activation stage we calculate the additional consequent truth degree. The production rule form was used for $\mathrm{FC} 1$ : $\sum \mathrm{F}_{\mathrm{j}}^{\mathrm{C}}$

If LG1 $=$ LG1i and $\mathrm{Fe}=\mathrm{Fei}$, then $\sum \mathrm{F}=\sum \mathrm{Fi}$ and $\sum \mathrm{F}=$

where $\mathrm{C}$ - the truth degree for a term $\sum \mathrm{F}$. 
The production rule bases were obtained for FC1, FC2. The production rule base for FC1 is shown in table 1 .

The center of gravity method applies for defuzzification.

\section{CONCLUSION}

The article deals with the method to improve the level control in the three-phase separator of «Hiter-Triter» type due to use of the fuzzy controller and its further optimization. Its application will allow to obtain both a higher control accuracy and computing power reduction. The increase in control accuracy of process parameters in its turn will enable to improve quality of the final product.

\section{References}

[1] K.A. Solovev, A.S. Nadyrshin, M.G. Bashirov, R.G. Sultanov, O.I. Sololoveva, K.A. Krishko, I.M. Gareyev, "Fuzzy controller with double base rules", Russian Federation patent for useful model №167890, The state register of useful models of the Russian Federation, Bulletin No. 2. 11.01.2017.

[2] E.A. Muravyova, E.A. Shulaeva, P.N.Charikov, R.R. Kadyrov, M.I. Sharipov, A.V. Bondarev, A.F. Shishkina, "Optimization of the structure of the control system using the fuzzy controller", Budapest, Hungary. Procedia Computer Science, vol. 120, pp. 487-494, 22-23 August 2017.

[3] E.A. Muravyova, M.I. Sharipov, "Method of fuzzy controller adaptation", Proceedings of the International Conference "Actual Issues of Mechanical Engineering" 2017 (AIME 2017), November 2017, doi:10.2991/aime-17.2017.82.

[4] V.V. Kruglov, M.I. Dli, Intellectual information systems: computer support of fuzzy logic and fuzzy inference systems, Moscow: Fizmatlit, 2002.

[5] A.V. Leonenkov, Fuzzy modeling in MATLAB environment and Fuzzy TECH, SPb .: BHV-Petersburg, 2005.

[6] S.D. Shtovba, Designing fuzzy systems using MATLAB, M.: hot line Telecom, 2007.

[7] S.D. Shtovba, Classification of objects based on fuzzy output, Exponenta Pro: Mathematics in applications, Vol. 1, pp.68-69, 2004.

[8] V.I. Gostev, Fuzzy controllers in automatic control systems, K .: Radioamator, 2008.

[9] V.I. Vasilyev, B.G. Ilyasov, Intelligent control systems. Theory and practice: a textbook, M .: Radiotekhnika, 2009.

[10] K.A. Pupkov, Methods of classical and modern theory of automatic control: A textbook in 5 volumes; 2 nd ed., Updated and revised TR: synthesis of controllers of automatic control systems, Moscow: Izdatelstvo MGTU im N.E. Bauman, 2004.

[11] E.A. Muravyova, G.A. Kayasheva, Patent No. 2309443 of the Russian Federation "Fuzzy controller with linguistic feedback for process control”, Bulletin of Inventions, № 39. 2007. 